\title{
Thermodynamics of Impurities in Pure Iron Obtained by Hydrogen Reduction
}

\author{
Yoshiaki KASHIWAYA* and Masakatsu HASEGAWA \\ Graduate School of Energy Science, Kyoto University, Yoshida Honmachi, Sakyoku, Kyoto, 606-8501 Japan. \\ (Received on February 21, 2012; accepted on June 25, 2012)
}

\begin{abstract}
Hydrogen itself is not a primary energy and needs an energy for its production, which means that $\mathrm{CO}_{2}$ will be exhausted during the production process, more or less. However, when a Green Hydrogen can be produced, it is a best way to use the hydrogen instead of carbon.

In this study, two kinds of iron ore were reduced and melted both under hydrogen and carbon atmosphere. The obtained iron metal under hydrogen atmosphere was quite pure one. The impurities in the metal were chemically and thermodynamically analyzed. The characteristics and benefits of hydrogen reduction were discussed in comparison with the carbon reduction.

The content of silicon in the metal under hydrogen atmosphere was one tenth to the iron obtained by carbon reduction. Manganese was about one third to one tenth against the carbon reduction. However, phosphorus in the hydrogen reduction was almost the same level to the carbon reduction. Sulfur content became half in the hydrogen reduction. Moreover, the content of hydrogen in the metal was the same level between the hydrogen reduction and the carbon reduction. It was found that the rate of hydrogen evolution from a molten metal during solidification was fast significantly. The activities of elements in the metal were calculated through the thermochemical data, and the relationships among those elements were elucidated.

From the thermodynamic analysis, a high oxygen activity in the metal obtained under hydrogen atmosphere caused to a low content of impurities and high activity of oxides related.
\end{abstract}

KEY WORDS: hydrogen reduction; clean steel; thermodynamic study of inclusion; activity; direct steelmaking.

\section{Introduction}

Hydrogen itself is not a primary energy and needs an energy and cost to produce, which means that $\mathrm{CO}_{2}$ will be exhausted during the production process, more or less. However, the circumstance related to energy supply is going to change, because the use of fossil fuels is limited which is not eternal one. Moreover, the countries having large population are arising economically and need an energy for developing their countries. $\mathrm{CO}_{2}$ content in the atmosphere is increasing and the environment of earth is changing quickly. We should cease to use the fossil fuel sooner or later, however, the time for ceasing is not clear and affected by an economic situation significantly. At the present time, Japan has a Fukushima's disaster of nuclear plants and Europe has a financial crisis. The reduction of $\mathrm{CO}_{2}$ emission seems to be tone down. Although such tide for $\mathrm{CO}_{2}$ reduction affected to the research situation, we should prepare for the situations with the best way or possible ways.

Hydrogen reduction of iron ore or iron oxide has been studied widely from about 90 years ago. H. Kamura is a one of the pioneer on the hydrogen reduction of iron ores. ${ }^{1,2)}$ The thermodynamic study and phase diagram work have been

\footnotetext{
* Corresponding author: E-mail: kashiwaya@energy.kyoto-u.ac.jp DOI: http://dx.doi.org/10.2355/isijinternational.52.1513
}

performed in the early stage of the 20th century and systematic integration has been done. ${ }^{3-7)}$ The reduction behaviors were analyzed in details and the mathematical models such as the shrinking core model ${ }^{8-13)}$ were developed and applied to an experimental and actual process data. On the basis of these fundamental studies, the understanding of reduction reaction of iron ore has been significantly promoted.

Although the hydrogen reduction has a high reaction rate in comparison with the $\mathrm{CO}$ reduction, the production of the hydrogen itself needs a cost and energy. The actual process of hydrogen reduction did not developed except the direct reduction process using the natural gas $\left(\mathrm{CH}_{4}\right.$ mainly). However, recently, the hydrogen reduction is focused on, because the problem of $\mathrm{CO}_{2}$ emission is the most important problem for the people living on the earth.

When the Green Hydrogen, which does not accompany with the $\mathrm{CO}_{2}$ emission, can be produced, the hydrogen reduction process can be an alternative process of the present ironmaking and steelmaking. In addition, when the residual fossil fuels are decreasing and the cost of fossil base energies are increasing drastically, the hydrogen process could be comparative with the present system.

Furthermore, the metallic iron obtained by hydrogen reduction is close to a pure iron without carbon. In addition, the tramp elements ( $\mathrm{Si}, \mathrm{Mn}$ and $\mathrm{P}$ ) cannot be reduced thermodynamically under hydrogen atmosphere (Eqs. (1), (2) 
and (3)). ${ }^{14)}$ On the other hand, most of inclusions such as $\mathrm{Si}$, $\mathrm{Mn}, \mathrm{P}$ are reduced by carbon and enter in the metallic iron in the lower part of BF (blast furnace) (Eqs. (1), (3) and (5)). ${ }^{14)}$

(a) Hydrogen reduction

$$
\begin{gathered}
\frac{1}{2} \mathrm{SiO}_{2(s)}+\mathrm{H}_{2(\mathrm{~g})}=\frac{1}{2} \mathrm{Si}_{(\mathrm{s})}+H_{2} O_{(g)} \\
\mathrm{MnO}_{(\mathrm{s})}+\mathrm{H}_{2(\mathrm{~g})}=\mathrm{Mn}_{(\mathrm{s})}+\mathrm{H}_{2} \mathrm{O}_{(\mathrm{g})} \ldots \\
\frac{1}{5} P_{2} \mathrm{O}_{5(s, l, g)}+H_{2(g)}=\frac{2}{5} P_{(s)}+H_{2} O_{(g)}
\end{gathered}
$$

(b) Carbon reduction

$$
\begin{gathered}
\frac{1}{2} \mathrm{SiO}_{2(s)}+\mathrm{C}_{(\mathrm{s})}=\frac{1}{2} \mathrm{Si}_{(\mathrm{s})}+C O_{(g)} \\
\mathrm{MnO}_{(s)}+\mathrm{C}_{(\mathrm{s})}=\mathrm{Mn}_{(\mathrm{s})}+C O_{(g)} . \\
\frac{1}{5} P_{2} \mathrm{O}_{5(s, l, g)}+C_{(g)}=\frac{2}{5} P_{(s)}+C O_{(g)}
\end{gathered}
$$

These features of hydrogen reduction should be especially focused on in this paper. This process leads to a 'Direct Steelmaking' in which just the addition processes of carbon and alloying elements are involved. If this direct steelmaking process was established, many processes such as the decarburization, desulfurization, dephosphorization and desiliconization were omissible in the entire conventional process.

In this study, two kinds of iron ore were reduced completely and then melted under hydrogen atmosphere, continuously. $\mathrm{CO}$ reduction was performed for the comparison with the results of hydrogen reduction. To clarify the reactions occurring in the systems, the thermodynamic study on the reduction reaction of impurities such as $\mathrm{Si}, \mathrm{Mn}, \mathrm{P}$ and $\mathrm{S}$ were performed.

\section{Experimental}

\subsection{Apparatus and Procedure}

Figure 1 shows the experimental apparatus for reduction and melting of iron ore. The furnace is an induction furnace and the reaction tube is a transparent quartz tube with $65 \mathrm{~mm} \phi$ O.D., $60 \mathrm{~mm} \phi$ I.D. and $500 \mathrm{mmL}$. The quartz reaction tube was sealed with a water cooled aluminum cap at the both end and the gas sealing was achieved by O-ring set to the aluminum cap.

The iron ore samples were reduced and melted in a porous alumina crucible. The sample crucible was set in a graphite crucible which worked as a susceptor for heating. Finally, the graphite susceptor was set in a larger and porous alumina crucible for insulation. The reaction gas was blew into the crucible by a dense alumna lance ( $6 \mathrm{~mm} \phi$ O.D., $4 \mathrm{~mm} \phi$ I.D. and $600 \mathrm{mmL}$ ) and the end of lance was set about $5 \mathrm{~mm}$ from the bottom of crucible in order to flow the reaction gas throughout the sample bed (Fig. 1(a)). As the total flow rate of reaction gas $\left(\mathrm{Ar}+24 \% \mathrm{H}_{2}, \mathrm{Ar}+24 \% \mathrm{CO}\right)$ was $500 \mathrm{~cm}^{3} / \min$ (STP), the linear velocity of the gas was $66 \mathrm{~cm} / \mathrm{s}$ which was high enough for eliminating the mass transfer control.

After the samples were reduced completely in a lower temperature $(1173 \mathrm{~K}-1373 \mathrm{~K})$, the alumina lance was pulled up to the top of sample bed as shown in Fig. 1(b), and the reduced samples were heated to a higher temperature (1873 K) for melting.

Figure 2 shows the heat pattern adopting in this experiment. The heating pattern consists of two periods. One is a reduction period and the other is a melting period. In this study, it is important that the reduction and melting operation were performed continuously without a taking out the sample from the crucible. This continuous reduction and melting process will give the thermodynamic advantage of hydrogen reduction as mentioned above.

In the reduction period, the sample was reduced at $1173 \mathrm{~K}$ for 2 hours, and then, the sample was reduced completely at $1373 \mathrm{~K}$ for $30 \mathrm{~min}$. These procedures were important to prevent the crucible erosion from the residual $\mathrm{FeO}$ in the melting period. The heating-up rate was $25 \mathrm{~K} / \mathrm{min}$ in the all steps and the cooling rate was about $50 \mathrm{~K} / \mathrm{min}$ for high temperature range above $1473 \mathrm{~K}$ and about $40 \mathrm{~K} / \mathrm{min}$ to $20 \mathrm{~K} / \mathrm{min}$ in the lower temperature range. The completely reduced sample was melted at $1873 \mathrm{~K}$ and hold about $30 \mathrm{~min}$. After that, the power of induction furnace was turned off and cooled down to the ambient temperature.

\subsection{Samples Served}

In this study, two kinds of sample were used. One was a sinter which was used for the actual blast furnace operation. The other was MBR (Minerações Brasileiras Reunidas) iron ore. The chemical compositions of the sinter and MBR ore

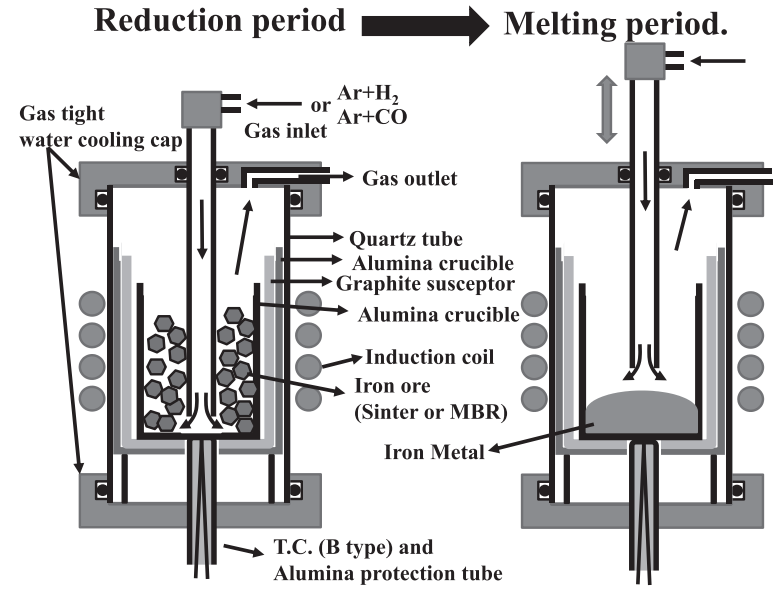

Fig. 1. Schematics of experimental apparatus.

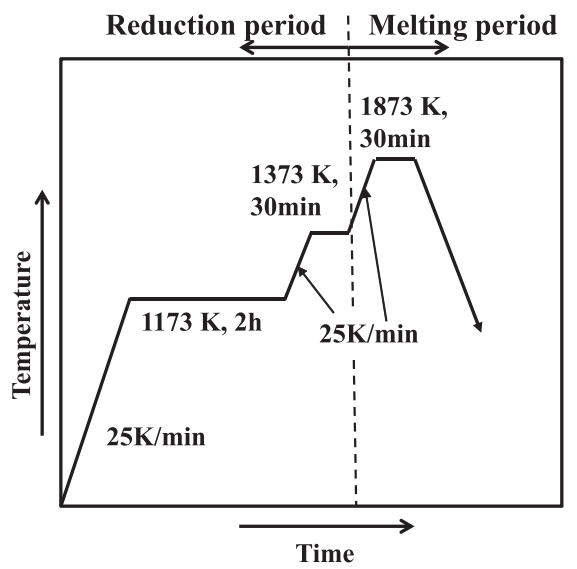

Fig. 2. Temperature profile of the reduction and melting experiment. 
are shown in Table 1. Total Fe (T.Fe) in the MBR ore is higher than that of sinter. The contents of $\mathrm{FeO}$ for sinter and MBR are $8.68 \%$ and $0.08 \%$, which means the MBR used in this experiment is a pure hematite iron ore.

The sinter was crushed and sieved into coarse particles from $2 \mathrm{~mm} \phi$ to $5 \mathrm{~mm} \phi$. As the MBR ore was a fine powder originally, it was once sintered at $1273 \mathrm{~K}$ under air atmosphere. Then, the obtained block type MBR ore was crushed and sieved to the same size of the sinter.

Table 2 shows the weights of samples used and the weight of metal button obtained after experiments. The notations ' $-\mathrm{H}$ ' and ' $\mathrm{C}$ ' mean the hydrogen reduction and the $\mathrm{CO}$ reduction, respectively. The yields of metal for hydrogen reduction were $95 \%$ to $97.6 \%$ and those for CO reduction were $97.7 \%$ to $99.9 \%$. In the case of sinter, as the content of $\mathrm{FeO}$ in slag will be high and remain until the melting period, the molten $\mathrm{FeO}$ slag will react with alumina crucible. It is the reason why the yield of metal for sinter

Table 1. Chemical compositions of iron ore used (mass\%).

\begin{tabular}{ccccccccccc}
\hline & T.Fe & $\mathrm{FeO}$ & $\mathrm{Fe}_{2} \mathrm{O}_{3}$ & $\mathrm{CaO}$ & $\mathrm{SiO}_{2}$ & $\mathrm{Al}_{2} \mathrm{O}_{3}$ & $\mathrm{MgO}$ & $\mathrm{MnO}$ & $\mathrm{S}$ & $\mathrm{P}$ \\
\hline Sinter & 60.57 & 8.68 & 76.82 & 8.42 & 4.92 & 1.76 & 0.99 & 0.22 & $<0.01$ & 0.06 \\
MBR & 67.66 & 0.08 & 96.66 & 0.28 & 1.36 & 0.62 & 0.06 & 0.13 & 0.004 & 0.03 \\
\hline
\end{tabular}

Table 2. Weight of samples used and metal obtained.

\begin{tabular}{ccccc}
\hline Sample Name & $\begin{array}{c}\text { Weight of } \\
\text { sample }(\mathrm{g})\end{array}$ & $\begin{array}{c}\text { Metal } \\
\text { obtained }(\mathrm{g})\end{array}$ & {$[\% \mathrm{C}]_{\mathrm{Fe}}$} & Yield of metal \\
\hline Sinter-H & 61.63 & 35.45 & 0.004 & $95.0 \%$ \\
MBR-H & 42.93 & 28.39 & 0.002 & $97.7 \%$ \\
Sinter-C & 61.16 & 38.10 & 5.15 & $97.6 \%$ \\
MBR-C & 48.67 & 34.52 & 4.68 & $99.9 \%$ \\
\hline
\end{tabular}

was slightly lower than that of MBR. The contents of carbon for Sinter-C and MBR-C are 5.15\% and 4.68\%, respectively. The contents of carbon are close to the saturation in the metal iron $(5.4 \%$ at $1873 \mathrm{~K})$. In the case of $\mathrm{CO}$ reduction, a graphite flake about $2 \mathrm{~g}$ was put in the bottom of crucible in order to reach the carbon saturation. However, as the carbon contents were lower than the saturation point, the reaction time (holding time of $30 \mathrm{~min}$ for melting at $1873 \mathrm{~K}$ in Fig. 2) might be short for reaching the complete saturation. From the result that the surface of solidified metal had an undissolved graphite pieces after experiment, it was considered that the effect of reaction time was relatively large.

\section{Results and Discussions}

\subsection{Analyses of Obtained Metals}

Figure 3 shows the appearances of metallic iron obtained. Sinter-H and MBR-H show a clear metallic color, although the top view of sinter-H shows a thin rust film which might come from an exposure to air before the complete cooling down. Sinter-C and MBR-C show an appearance of cast iron. As indicating by arrows, some of graphite flake undissolved are attached on the surface of button. These buttons are cut and polished for the observation of microstructure.

Figure 4 shows the typical photos of the microstructures for measuring the Index of Cleanliness of Steel (d, Eq. (7)) which is measured by counting the number of inclusions in the 60 fields with 400 grids. The total area for measuring is about $300 \mathrm{~mm}^{2}$. The largest inclusion was about $5 \mu \mathrm{m}$ in diameter both for sinter-H and MBR-H. The index of cleanliness for sinter-H was $0.121 \%$ and $0.017 \%$ for MBR-H, these values are quite small one.

Index of cleanliness: $\quad \mathrm{d}=\mathrm{n} /(\mathrm{p} \times \mathrm{f}) \times 100$.

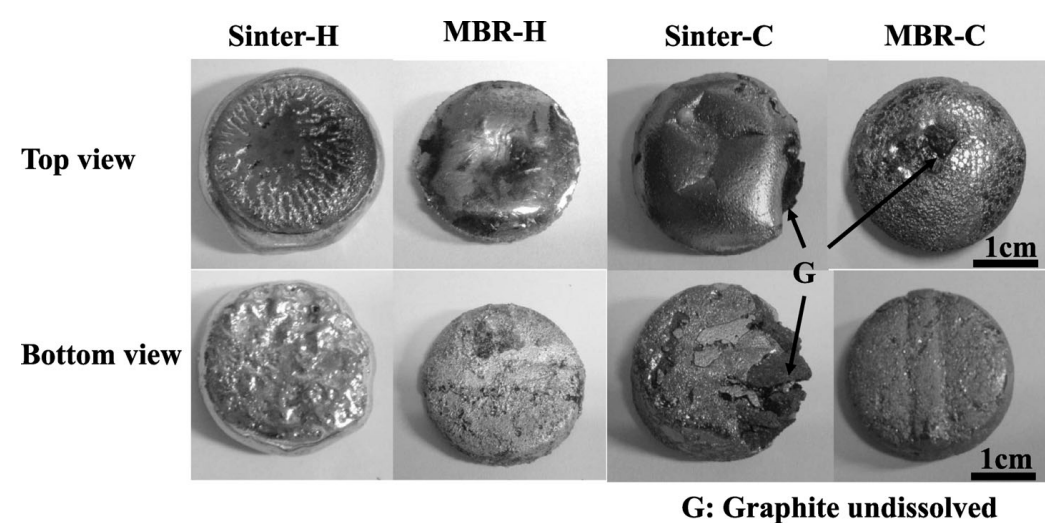

Fig. 3. Outlooks of iron buttons obtained.

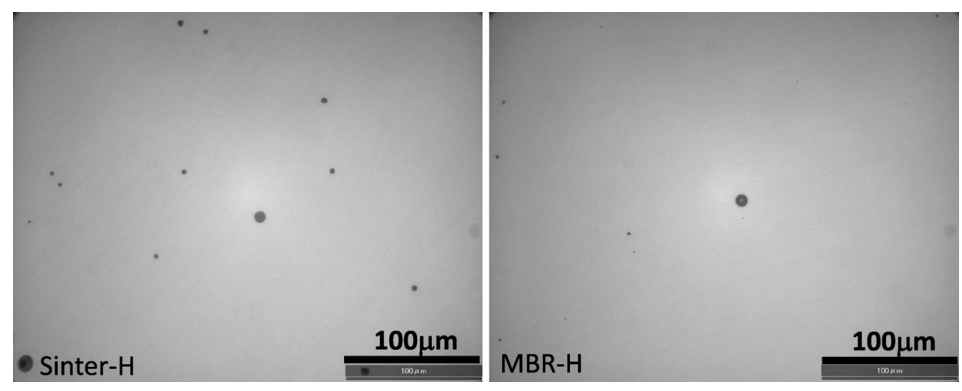

Fig. 4. Inclusions in the metals obtained under hydrogen atmosphere for Sinter- $\mathrm{H}$ and MBR-H (Sinter-H: $\mathrm{d}=\mathrm{n} /$ $(400 \times 60) \times 100=0.121 \%$, MBR-H: $d=0.017 \%)$. 
where n: number of inclusion, $\mathrm{p}$ : number of grid, f: number of field.

Sinter-H: $d=0.121 \%$

MBR-H: $\mathrm{d}=0.017 \%$

In Fig. 5, the result of EDS analysis of inclusion of sinter$\mathrm{H}$ is shown. The inclusion is an oxide consisted of $\mathrm{Si}$ and Al base. This aluminosilicate contains small content of $\mathrm{Ca}$ and Mn. Figure 6 shows the result of EDS analysis of inclusion in MBR-H. This inclusion separated into two phases. The inside of inclusion is $\mathrm{FeO}$ and the outside is an oxide of $\mathrm{FeO}-\mathrm{SiO}_{2}$ system, which will be a fayalite $\left(2 \mathrm{FeO} \cdot \mathrm{SiO}_{2}\right)$. From the $\mathrm{FeO}-\mathrm{SiO}_{2}$ binary phase diagram, the melt separates into two phases consisted of wustite and fayalite. In addition, the fayalite includes some content of phosphorus, but little aluminum oxide. Figure 7 shows the microstructure of sinter-C and MBR-C. Since both of samples are close to the carbon saturated iron, the microstructure shows almost the same structure of cast iron and many graphite flakes precipitated in the sample.

Table 3 shows the chemical composition of metals obtained in this experiment. These results are compared in Figs. 8 and 9. Figure 8 shows the comparison of the contents of $\mathrm{C}, \mathrm{Si}, \mathrm{Mn} \mathrm{P}, \mathrm{Al}$ and $\mathrm{O}$. Each column corresponds to the respective elements, the left hand side pair of bar in a column corresponds to the sinter-H and MBR-H, and the right hand side pair corresponds to the sinter-C and MBR-C.

Carbon contents of sinter-H and MBR-H are $40 \mathrm{ppm}$ and $20 \mathrm{ppm}$, respectively. These carbons might come from the graphite susceptor. If other heating system without carbon material was used in the reaction system, the carbon content would be under the limit of analysis. Actually, since the pure iron needs a carbon addition together with the alloying elements for the production of steel, the small content of carbon in iron obtained by hydrogen reduction is not so important problem.

Silicon contents of sinter-H and MBR-H are significantly lower than that of carbon reduction, that is excellent agree with the thermodynamic consideration mentioned above. Manganese contents of sinter-H and MBR-H are also low and about one third to one tenth for the carbon reduction. The manganese content also coincides with the thermodynamic prediction.

On the other hand, phosphorus contents of sinter-H and MBR-H are almost the same level with the carbon reduction. In this experiment, slag was not used and the equilibrium would establish in the contact between the alumina crucible and metal reduced. It is considered that the most of oxide impurities in the iron ore will react with the crucible. In addition, some of $\mathrm{FeO}$ remained will also react with the crucible. The detailed thermodynamic consideration were performed in the later section.

It is considered that the aluminum contents of sinter- $\mathrm{H}$ and MBR-H are to be a same level with the carbon reduction. However, $\mathrm{Al}$ in MBR-H is relatively high and $\mathrm{Al}$ in Sinter-H is under the limit of analysis. Although the meaning of these results is not known in this stage, the content of $\mathrm{Al}$ is not decided by the results of hydrogen and carbon reduction.

The oxygen level is high in the hydrogen reduction, which is characteristics in the hydrogen system, and the content of oxygen is from $140 \mathrm{ppm}$ to $245 \mathrm{ppm}$, while the one in carbon reduction is from $29 \mathrm{ppm}$ to $75 \mathrm{ppm}$.

Figure 9 shows the comparison of the contents of $\mathrm{S}, \mathrm{Ca}$, $\mathrm{Mg}$ and $\mathrm{H}$ in the metal obtained. The contents of $\mathrm{S}$ of sinter$\mathrm{H}$ and MBR-H are less than half of the ones of sinter-C and MBR-C. The contents of $\mathrm{Ca}$ and $\mathrm{Mg}$ are difficult to under-

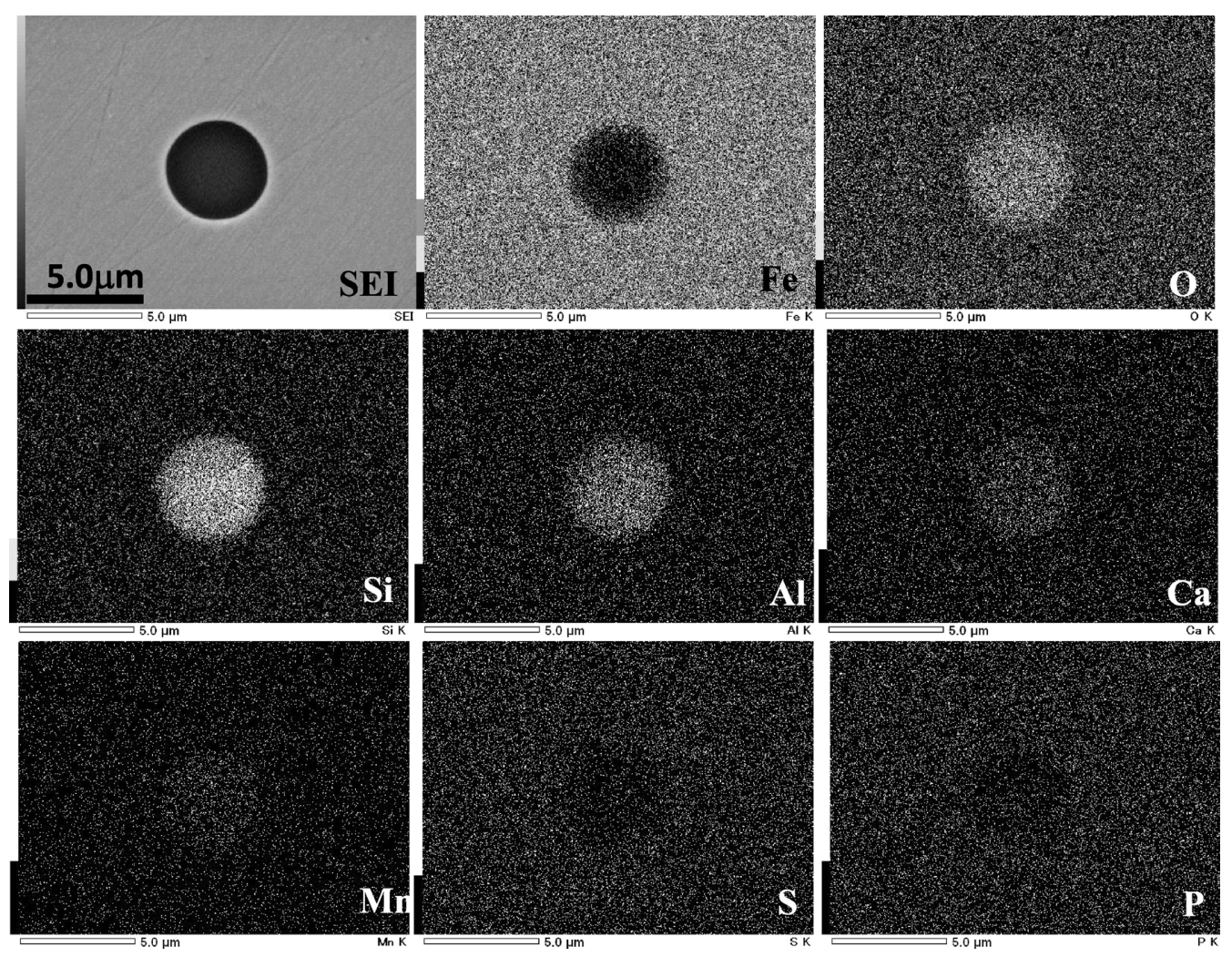

Fig. 5. EDS mapping of inclusion in Sinter-H. 


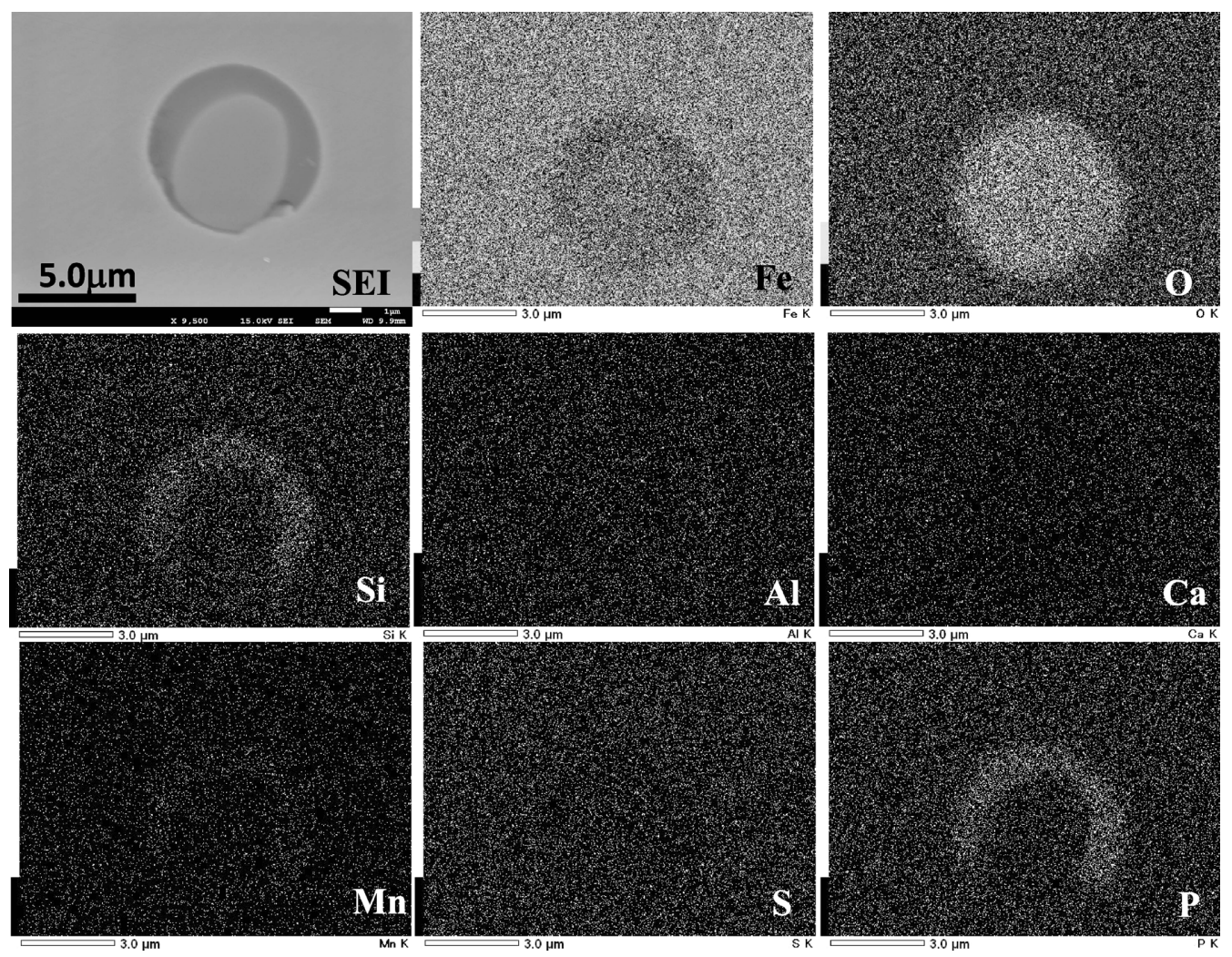

Fig. 6. EDS mapping of inclusion in MBR-H.

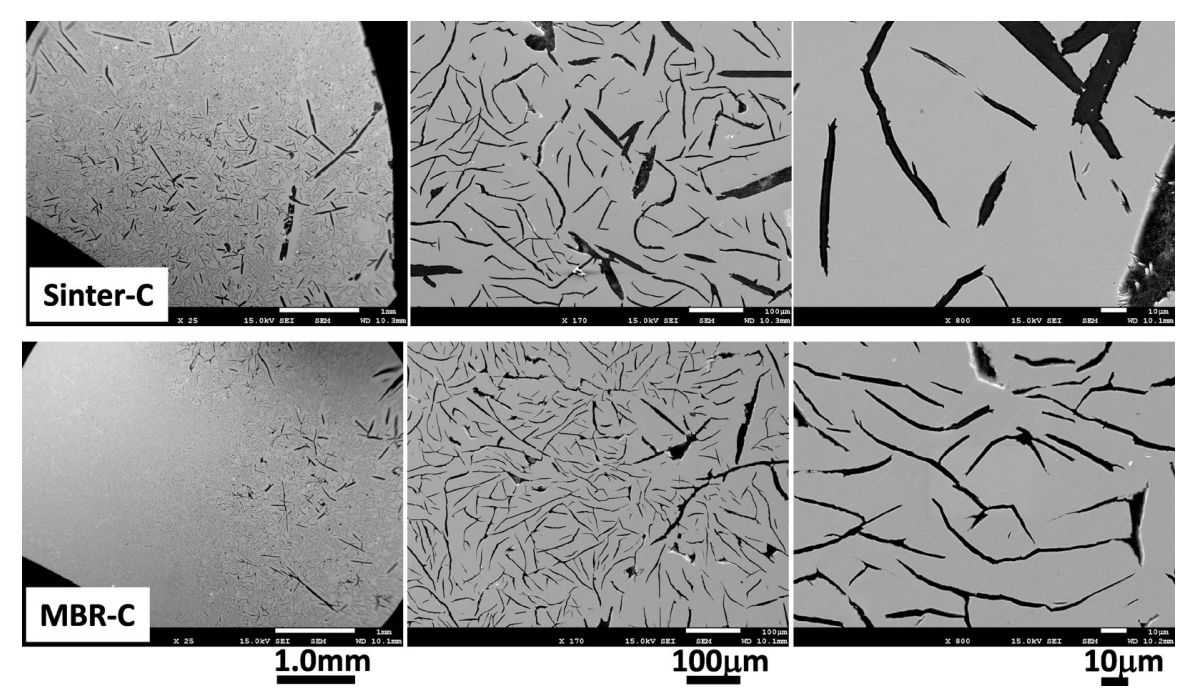

Fig. 7. Microstructure of iron with high carbon content (Sinter-C: $5.15 \%$, MBR-C: $4.68 \%$ ).

Table 3. Chemical composition in metal obtained.

\begin{tabular}{c|ccccc|rcccc}
\hline & \multicolumn{7}{|c|}{ mass\% } & \multicolumn{4}{|c}{ ppm } \\
\hline $\begin{array}{c}\text { Sample } \\
\text { Name }\end{array}$ & $\mathrm{C}$ & $\mathrm{Si}$ & $\mathrm{Mn}$ & $\mathrm{P}$ & $\mathrm{Al}$ & $\mathrm{O}$ & $\mathrm{Ca}$ & $\mathrm{S}$ & $\mathrm{Mg}$ & $\mathrm{H}$ \\
\hline Sinter-H & 0.004 & 0.02 & 0.05 & 0.071 & $<0.001$ & 0.0139 & $<3$ & 20 & $<3$ & 1.0 \\
MBR-H & 0.002 & $<0.01$ & $<0.01$ & 0.044 & 0.028 & 0.0245 & 5 & $<10$ & $<3$ & 1.4 \\
Sinter-C & 5.15 & 0.09 & 0.17 & 0.089 & 0.005 & 0.0075 & 17 & 40 & $<3$ & 1.2 \\
MBR-C & 4.68 & 0.21 & 0.09 & 0.047 & 0.009 & 0.0029 & 5 & 40 & $<3$ & 1.4 \\
\hline
\end{tabular}

stand, so that the level of these elements are very low. On the other hand, it is interesting to know the hydrogen content of sinter-H and MBR-H. Even in a melting and solidifying the iron under hydrogen atmosphere, the hydrogen content

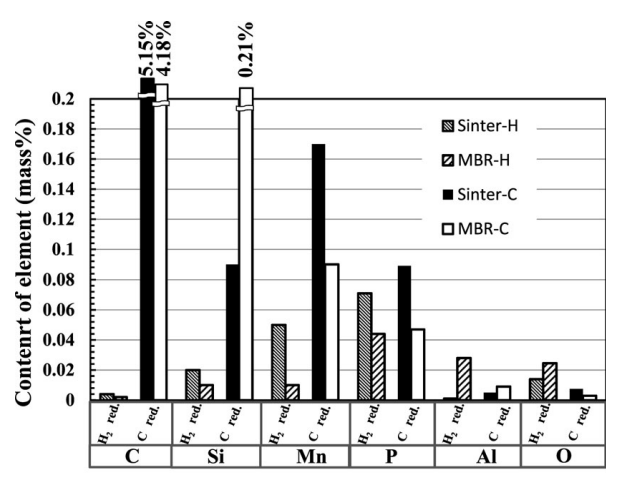

Elements in metal obtained

Fig. 8. Comparison of contents of impurities between hydrogen reduction and carbon reduction $(\mathrm{C}, \mathrm{Si}, \mathrm{Mn}, \mathrm{P}, \mathrm{Al}$ and $\mathrm{O})$. 
was very low and the same level with carbon reduction without hydrogen in the atmosphere. It could be concluded that the hydrogen absorbed in the iron melt was quickly evolved to the atmosphere during solidification. Since the hydrogen brittleness occurs in the welding, heating and plating process mainly, hydrogen reduction process is not necessary to take into account the hydrogen content in the solidified iron.

\section{Thermodynamics of Impurities in the Metal Obtained}

\subsection{Reduction of Impurities by $\mathbf{C}$ and $\mathbf{H}$}

The activity coefficients for the respective elements were calculated using the interaction parameters published by JSPS $^{15)}$ and the values used were summarized in Table 4. The calculated activity coefficients and the estimated activities are shown in Table 5.

\subsection{1. $\mathrm{SiO}_{2}$}

The change of Gibb's energy for the reduction of $\mathrm{SiO}_{2}$ by dissolved hydrogen $(\underline{\mathrm{H}})$ in the molten iron (Eq. (11)) is estimated using Eqs. (8)-(10). The thermodynamic data of the related elements are mainly adopted from the data book. ${ }^{15)}$ Also, the $\mathrm{SiO}_{2}$ reduction by dissolved carbon (ㄷ) in molten iron (Eq. (13)) can be estimated using Eqs. (8) and (12).

JSPS:

$\mathrm{SiO}_{2(s)}=\underline{\mathrm{Si}}+2 \underline{O}$, $\Delta \mathrm{G}^{\circ} / J=576430-218.4 \cdot \mathrm{T}$

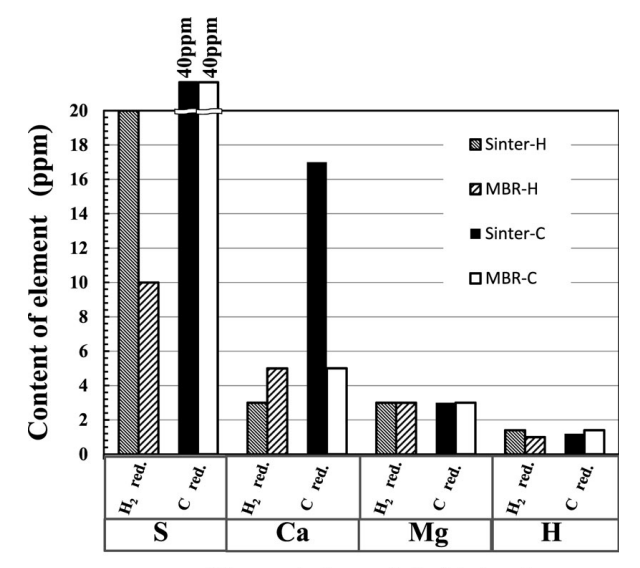

Elements in metal obtained

Fig. 9. Comparison of contents of impurities between hydrogen reduction and carbon reduction $(\mathrm{S}, \mathrm{Ca}, \mathrm{Mg}, \mathrm{H})$.

$$
\frac{1}{2} H_{2(g)}=\underline{H}, \quad \Delta \mathrm{G}^{\circ} / J=36460+30.46 \cdot \mathrm{T}
$$

$$
H_{2(g)}+\underline{O}=H_{2} O_{(g)},
$$$$
\Delta \mathrm{G}^{\circ} / J=-134800+61.71 \cdot \mathrm{T}
$$

$$
\mathrm{SiO}_{2(s)}+4 \underline{\mathrm{H}}=\underline{\mathrm{Si}}+2 \mathrm{H}_{2} \mathrm{O}_{(g)}, \quad \Delta \mathrm{G}^{\circ} / J=160990-216.8 \cdot \mathrm{T}
$$

$$
\underline{C}+\underline{\mathrm{O}}=C \mathrm{O}_{(g)},
$$$$
\Delta \mathrm{G}^{\circ} / J=-22200-38.33 \cdot \mathrm{T}
$$

$$
\mathrm{SiO}_{2(s)}+2 \underline{\mathrm{C}}=\underline{\mathrm{S}} \underline{i}+2 C O_{(g)}, \quad \Delta \mathrm{G}^{\circ} / J=532030-295.1 \cdot \mathrm{T}
$$

Using Eqs. (11) and (13), the variations of activities of silicon $\left(a_{S i}\right)$ were calculated and plotted in the Fig. 10. In the case of hydrogen reduction (Eq. (11)), the activity of $\mathrm{H}$ was assumed to be $1 \times 10^{-4}$, because the $\log a_{H}$ obtained by the experiment was -3.997 and -3.851 (Table 5). The activity of $\mathrm{SiO}_{2}\left(a_{\mathrm{SiO}_{2}}\right)$ was assumed to be 1.0. The $\log a_{\mathrm{Si}}$ was -1.692 for sinter-H (ם) and -1.996 for MBR-H $(\square)$. In order to fit these values, the partial pressure of $\mathrm{H}_{2} \mathrm{O}\left(\mathrm{P}_{\mathrm{H}_{2} \mathrm{O}}\right)$ was $1.9 \times 10^{-4}$ for sinter-H and $2.7 \times 10^{-4}$ for MBR-H.

On the other hand, the silicon activities of carbon reduction ( $a_{S i}$, Eq. (13)) were estimated using $a_{C}=38$ and $\mathrm{P}_{\mathrm{CO}}=0.24$ both for sinter-C and MBR-C. The Henrian activity of carbon $\left(a_{C}=38\right)$ was estimated from Eqs. (14) and (15) at $1873 \mathrm{~K}$.

\begin{tabular}{|c|c|c|c|c|c|c|c|c|c|c|c|c|c|c|c|c|}
\hline & \multicolumn{4}{|c|}{ Sinter-H } & \multicolumn{4}{|c|}{ MBR-H } & \multicolumn{4}{|c|}{ Sinter-C } & \multicolumn{4}{|c|}{ MBR-C } \\
\hline & {$[\% i]$} & $\log f_{i}$ & $a_{i}$ & $\log \boldsymbol{a}_{\boldsymbol{i}}$ & {$[\% i]$} & $\log f_{i}$ & $a_{i}$ & $\log \boldsymbol{a}_{i}$ & {$[\% \boldsymbol{i}]$} & $\log f_{i}$ & $a_{i}$ & $\log \boldsymbol{a}_{\boldsymbol{i}}$ & {$[\% i]$} & $\log f_{i}$ & $a_{i}$ & $\log a_{i}$ \\
\hline $\mathrm{Al}$ & 0.001 & -0.02356 & 9.47E-04 & -3.024 & 0.028 & -0.04504 & $2.52 \mathrm{E}-02$ & -1.598 & 0.005 & 0.462161 & $1.45 \mathrm{E}-02$ & -1.839 & 0.009 & 0.43401 & $2.44 \mathrm{E}-02$ & -1.612 \\
\hline $\mathrm{C}$ & 0.004 & 0.00148 & $4.01 \mathrm{E}-03$ & -2.396 & 0.002 & -0.00307 & $1.99 \mathrm{E}-03$ & -2.702 & 5.15 & 1.259652 & 93.6 & 1.971 & 4.68 & 1.15499 & 66.9 & 1.852 \\
\hline $\mathrm{H}$ & 0.0001 & 0.00249 & $1.01 \mathrm{E}-04$ & -3.998 & 0.00014 & 0.00264 & $1.41 \mathrm{E}-04$ & -3.851 & 0.00012 & 0.31293 & $2.47 \mathrm{E}-04$ & -3.608 & 0.00014 & 0.287325 & $2.71 \mathrm{E}-04$ & -3.567 \\
\hline Mn & 0.05 & -0.00606 & 4.93E-02 & -1.307 & 0.01 & -0.00536 & $9.88 \mathrm{E}-03$ & -2.005 & 0.17 & 0.21381 & $1.04 \mathrm{E}-01$ & -0.983 & 0.09 & -0.19424 & $5.57 \mathrm{E}-02$ & -1.240 \\
\hline $\mathrm{O}$ & 0.0139 & -0.00181 & $1.38 \mathrm{E}-02$ & -1.859 & 0.0245 & -0.03516 & $2.26 \mathrm{E}-02$ & -1.646 & 0.0075 & -0.824579 & $1.12 \mathrm{E}-03$ & -2.950 & 0.0029 & -0.76336 & $5.00 \mathrm{E}-04$ & -3.301 \\
\hline $\mathrm{P}$ & 0.071 & 0.00666 & $7.21 \mathrm{E}-02$ & -1.142 & 0.044 & 0.00760 & $4.48 \mathrm{E}-02$ & -1.349 & 0.089 & & $4.05 \mathrm{E}-01$ & -0.392 & 0.047 & 0.61102 & $1.92 \mathrm{E}-01$ & -0.717 \\
\hline $\mathrm{S}$ & 0.002 & -0.00063 & $2.00 \mathrm{E}-03$ & -2.700 & 0.001 & -0.00320 & 9.93E-04 & -3.003 & 0.004 & 0.575140 & $1.50 \mathrm{E}-02$ & -1.823 & 0.004 & 0.533994 & $1.37 \mathrm{E}-02$ & -1.864 \\
\hline $\mathrm{Si}$ & 0.02 & 0.00704 & 2.03E-02 & -1.692 & 0.01 & 0.00407 & $1.01 \mathrm{E}-02$ & -1.996 & 0.09 & 0.941536 & 7.87E-01 & -0.104 & 0.21 & 0.867477 & $1.55 \mathrm{E}+00$ & 0.190 \\
\hline
\end{tabular}

Table 4. Interaction parameters used in the present study. $\left(\mathrm{e}_{i}{ }^{j}: \operatorname{most}\right.$ values are from $\mathrm{JSPS}^{15)}$ ).

\begin{tabular}{ccccccccc}
\hline$i j$ & $\mathrm{Al}$ & $\mathrm{C}$ & $\mathrm{H}$ & $\mathrm{Mn}$ & $\mathrm{O}$ & $\mathrm{P}$ & $\mathrm{S}$ & $\mathrm{Si}$ \\
\hline $\mathrm{Al}$ & 0.043 & 0.091 & 0.24 & 0 & -1.98 & 0.033 & 0.035 & 0.056 \\
$\mathrm{C}$ & 0.043 & 0.243 & 0.67 & -0.0084 & -0.32 & 0.051 & 0.044 & 0.078 \\
$\mathrm{H}$ & 0.013 & 0.06 & 0 & -0.002 & 0.05 & 0.015 & 0.017 & 0.027 \\
$\mathrm{Mn}$ & -0.012 & -0.04 & -0.34 & 0 & -0.083 & -0.06 & -0.048 & -0.0173 \\
$\mathrm{O}$ & -1.17 & $-0.158^{*}$ & 0.73 & -0.021 & -0.174 & 0.07 & -0.133 & -0.066 \\
$\mathrm{P}$ & 0.037 & 0.126 & 0.33 & -0.032 & 0.13 & 0.054 & 0.034 & 0.099 \\
$\mathrm{~S}$ & 0.041 & 0.111 & 0.41 & -0.026 & -0.27 & 0.035 & -0.046 & 0.075 \\
$\mathrm{Si}$ & 0.058 & 0.18 & 0.64 & -0.0146 & -0.119 & 0.09 & 0.066 & 0.103 \\
\hline
\end{tabular}

*Y. Kashiwaya, et al.; Steel research International, vol. 81, 2010, No. 4.

Table 5. Henrian activity and activity coefficient of elements in metal obtained. 


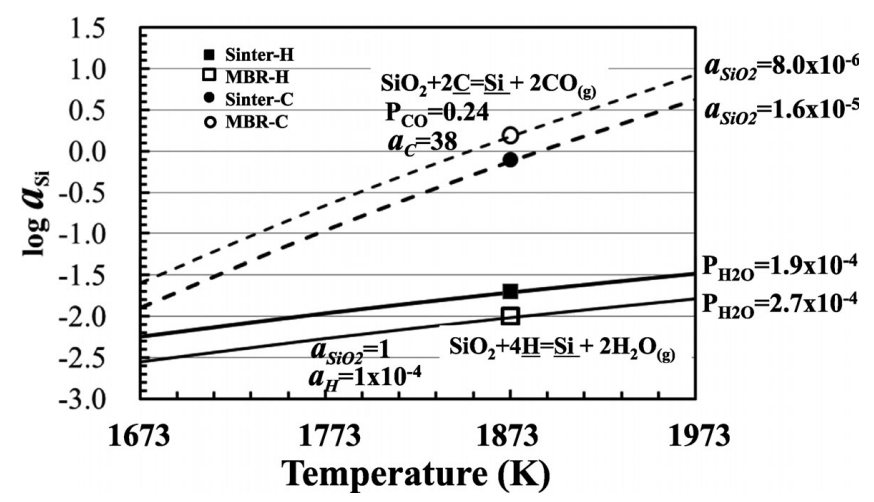

Fig. 10. Variations of silicon activity for $\mathrm{SiO}_{2}$ reductions by hydrogen and carbon.

$$
\begin{aligned}
& \mathrm{C}_{(\mathrm{gr})}=\underline{\mathrm{C}}, \quad \quad \Delta \mathrm{G}^{\circ} / \mathrm{J}=23484.8-43.51 \cdot \mathrm{T} \ldots \ldots(14)^{14,15)} \\
& a_{C}(\text { Henry })=\exp \left(\frac{-\Delta G^{\circ}}{R T}\right)
\end{aligned}
$$

While the experimental carbon activities $\left(a_{C}\right)$ for sinter-C and MBR-C are 93.6 and 66.9 (Table 5), respectively, which are agree with the value obtained by Eqs. (14) and (15).

The activities of silicon $\left(\log a_{S i}\right)$ for Sinter-C and MBR-C were $-0.104(\bigcirc)$ and $+0.19(\bigcirc)$, respectively, when the activities of $\mathrm{SiO}_{2}\left(a_{\mathrm{SiO}_{2}}\right)$ were assumed to be $8 \times 10^{-6}$ and $1.6 \times 10^{-5}$ (Fig. 10), respectively. The temperature dependence of $a_{S i}$ of carbon reduction is larger than that of hydrogen reduction. In addition, the activity of $\mathrm{SiO}_{2}, a_{\mathrm{SiO}_{2}}$ of carbon reduction is significantly lower than that of hydrogen reduction.

\subsection{2. $\mathrm{MnO}$}

The activity of $\mathrm{MnO}$ was estimated by Eq. (16) using the activities of oxygen $(\mathrm{O})$ and manganese $(\underline{\mathrm{Mn}})$ obtained by the experiment.

$$
\mathrm{MnO}=\underline{\mathrm{Mn}}+\underline{\mathrm{O}} \quad \Delta \mathrm{G}^{\circ} / \mathrm{J}=288200-129.3 \mathrm{~T} \ldots .(16)^{15)}
$$

The activities of Mn $\left(\log a_{M n}\right)$ for Sinter-H and MBR-H are -1.307 and -2.005 , respectively. Since the oxygen activity $\left(a_{O}\right)$ of hydrogen reduction is higher than that of carbon reduction, it is considered that the activity of $\mathrm{MnO}\left(a_{\mathrm{MnO}}\right)$ will be higher than that of carbon reaction. Using Eq. (16), the relationship between $\log a_{O}$ and $\log a_{M n}$ was calculated and plotted in Fig. 11 with the assumption of the activity of $\mathrm{MnO}\left(a_{\mathrm{MnO}}\right)$. As a result, the activity of $\mathrm{MnO}\left(a_{\mathrm{MnO}}\right)$ for the hydrogen reduction was about 0.01 ( 0.01 for sinter-H and 0.005 for MBR-H), and the one for the carbon reduction was about 0.0005 (0.002 for sinter-C and 0.0005 for MBR-C).

\subsection{3. $\mathrm{S}$ in Molten Iron}

The activities of sulfur in molten iron $\left(a_{S}\right)$ was considered through two reactions. One is the equilibrium among $\mathrm{H}_{2} \mathrm{~S}(\mathrm{~g}), \mathrm{H}$ and $\mathrm{S}$. The $\Delta \mathrm{G}^{\circ}$ of Eq. (19) can be calculated by Eqs. (17) and (18).

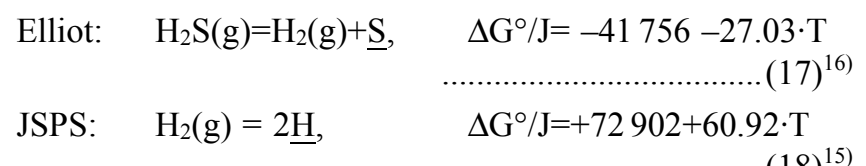

$$
\mathrm{H}_{2} \mathrm{~S}(\mathrm{~g})=2 \underline{\mathrm{H}}+\underline{\mathrm{S}} \quad \Delta \mathrm{G}^{\circ} / \mathrm{J}=+31146+33.89 \cdot \mathrm{T}
$$

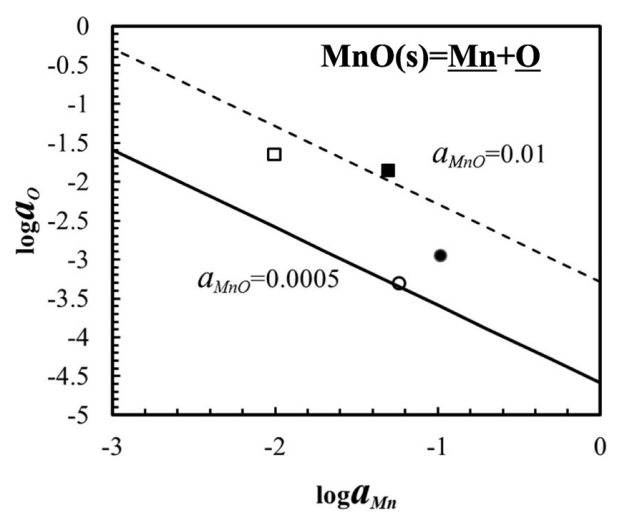

Fig. 11. Relationship of activity between $\mathrm{Mn}$ and $\mathrm{O}$ in the molten iron (Hydrogen reduction: $\mathrm{a}_{\mathrm{MnO}}=0.01$, Carbon reduction: $\left.\mathrm{a}_{\mathrm{MnO}}=0.0005\right)$.

The other is a desulfurization reaction by $\mathrm{CaO}$ together with the deoxidation reaction by Aluminum (Eq. (25)), which is estimated by Eqs. (20)-(24).

$\mathrm{Al}_{(1)}=\underline{\mathrm{Al}}$,

$\Delta \mathrm{G}^{\circ} / \mathrm{J}=-43095.2-32.26 \cdot \mathrm{T}$

$\frac{1}{2} \mathrm{~S}_{2(\mathrm{~g})}=\underline{\mathrm{S}}$,

$\Delta \mathrm{G}^{\circ} / \mathrm{J}=-131880+22.05 \cdot \mathrm{T}$

$2 \mathrm{Al}_{(\mathrm{l})}+\frac{2}{3} \mathrm{O}_{2(\mathrm{~g})}=\mathrm{Al}_{2} \mathrm{O}_{3}$,

$\Delta \mathrm{G}^{\circ} / \mathrm{J}=-1679880+321.8 \cdot \mathrm{T}$

$\mathrm{Ca}_{(\mathrm{l})}+\frac{1}{2} \mathrm{~S}_{2(\mathrm{~g})}=\mathrm{CaS}_{(\mathrm{s})}$

$\Delta \mathrm{G}^{\circ} / \mathrm{J}=-552706+108.4 \cdot \mathrm{T}$

$\mathrm{Ca}_{(\mathrm{l})}+\frac{1}{2} \mathrm{O}_{2(\mathrm{~g})}=\mathrm{CaO}_{(\mathrm{s})}$

$\Delta \mathrm{G}^{\circ} / \mathrm{J}=-639524.4+107.9 \cdot \mathrm{T}$

$\mathrm{CaO}+\frac{2}{3} \underline{\mathrm{Al}}+\underline{\mathrm{S}}=\mathrm{CaS}+\frac{1}{3} \mathrm{Al}_{2} \mathrm{O}_{3}, \quad \Delta \mathrm{G}^{\circ} / \mathrm{J}=-312528+107.28 \cdot \mathrm{T}$

Figure 12 shows the relationship between $\log a_{S}$ and $\log$ $a_{H}$, which is obtained using Eq. (19). In Fig. 12, the values obtained by the experiments are plotted with respective marks ( $\square$ : sinter-H, $\square$ : MBR-H, ๑: sinter-C, $\bigcirc$ : MBR-C). When the equilibrium $\mathrm{P}_{\mathrm{H} 2 \mathrm{~S}}$ for hydrogen reduction and carbon reduction were assumed to be $2 \times 10^{-8}$ and $2 \times 10^{-5}$, respectively, it was found that the relationship between $\log$ $a_{S}$ and $\log a_{H}$ by the calculation can agree with the observations as shown in Fig. 12. The both values of $a_{H}$ and $a_{S}$ for sinter-H and MBR-H are lower than that of sinter-C and MBR-C. Although the reason of this result is not clear at this stage, it might be related to the high oxygen activity $\left(a_{O}\right)$ in the hydrogen reduction.

Figure 13 shows the relationship between $\log a_{A l}$ and $\log$ $a_{S}$, which are calculated using Eq. (39). When the ratios of activity of $\mathrm{CaO}$ to $\mathrm{CaS}\left(a_{\mathrm{CaO}} / a_{\mathrm{CaS}}\right)$ are assumed to be 20 and 1 for hydrogen reduction and carbon reduction, respectively, and the activity of $\mathrm{Al}_{2} \mathrm{O}_{3}$ is assumed to be unity, the calculation results are agree with the observations. From this result, it is considered that the lower sulfur activity in the hydrogen reduction is caused by the higher $\mathrm{CaO}$ activity 


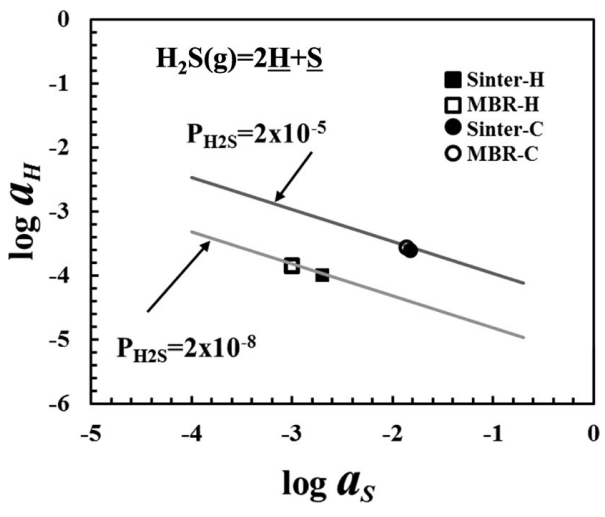

Fig. 12. Relationship of activity between $S$ and $H$ in the molten iron (Hydrogen reduction: $\mathrm{P}_{\mathrm{H}_{2} \mathrm{~S}}=2 \times 10^{-8}$, Carbon reduction: $\mathrm{P}_{\mathrm{H}_{2}} \mathrm{~S}=2 \times 10^{-5}$ ).

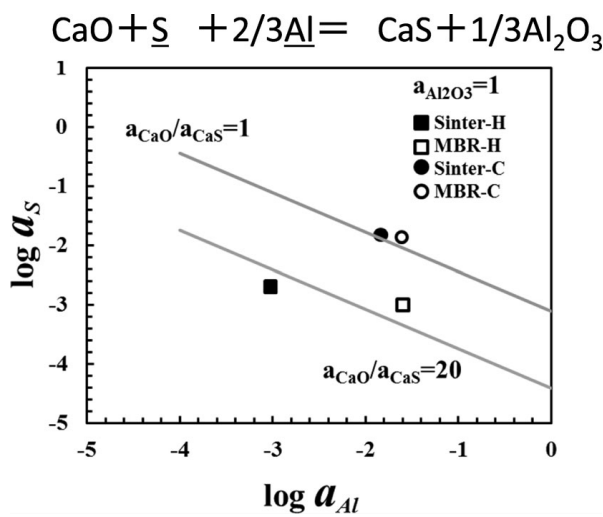

Fig. 13. Relationship of activity between $\mathrm{Al}$ and $\mathrm{S}$ in the molten iron (Hydrogen reduction: $\mathrm{a}_{\mathrm{CaO}} / \mathrm{a}_{\mathrm{Cas}}=20$, Carbon reduction: $\mathrm{a}_{\mathrm{CaO}} / \mathrm{a}_{\mathrm{CaS}}=1$ ).

owing to the higher oxygen potential.

\subsection{4. $\mathrm{P}_{2} \mathrm{O}_{5}$}

The $\mathrm{P}_{2} \mathrm{O}_{5}$ reduction reaction by hydrogen (Eq. (26)) is basically the same reaction as Eq. (3), but the state of phosphorus in the product is different between two reactions. The linear temperature dependence of $\Delta \mathrm{G}^{\circ}$ of Eq. (26) was obtained by author using thermochemical database. ${ }^{14)}$ The $\mathrm{P}_{2} \mathrm{O}_{5}$ reduction by dissolved hydrogen $(\mathrm{H})(\mathrm{Eq} .(29))$ is estimated by Eqs. (26)-(28). Using Eq. (29), the relationship between $\log a_{H}$ and $\log a_{P}$ is plotted in Fig. 14. The partial pressure of $\mathrm{H}_{2} \mathrm{O}, \mathrm{P}_{\mathrm{H}_{2} \mathrm{O}}$ was assumed to be $2.5 \times 10^{-4}$, which was the same value with $\mathrm{SiO}_{2}$ reduction as shown in Fig. 10. When the activities of $\mathrm{P}_{2} \mathrm{O}_{5}, a_{P_{2} O_{5}}$ is $5 \times 10^{-19}$ and $1 \times 10^{-20}$ for sinter-H and MBR-H, respectively, the calculation results of the relationship between $\log a_{H}$ and $\log a_{P}$ is good agreement with the experiment results.

JSPS:

$$
P_{2} \mathrm{O}_{5(s)}+5 H_{2(g)}=P_{2(g)}+5 H_{2} O_{(g)}, \Delta \mathrm{G}^{\circ} / J=371400-62.9 \cdot \mathrm{T}
$$

$P_{2(g)}=2 \underline{P}$, $\Delta \mathrm{G}^{\circ} / J=-315700+10.79 \cdot \mathrm{T}$

$\frac{1}{2} H_{2(g)}=\underline{H}$, $\Delta \mathrm{G}^{\circ} / J=36459.4+30.5 \cdot \mathrm{T}$

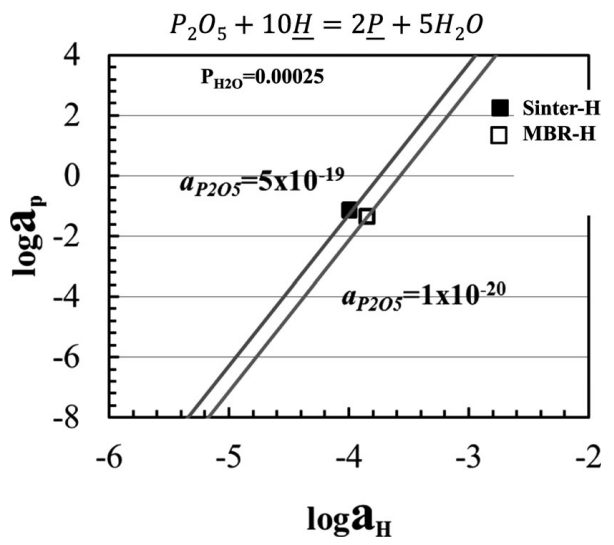

Fig. 14. Relationship of activity between $\mathrm{H}$ and $\mathrm{P}$ in the case of hydrogen reduction: $\mathrm{a}_{2} \mathrm{O}_{5}=1 \times 10^{-20}$ or $5 \times 10^{-15}, \mathrm{P}_{\mathrm{H}_{2} \mathrm{O}}=$ $2.5 \times 10^{-4}$.

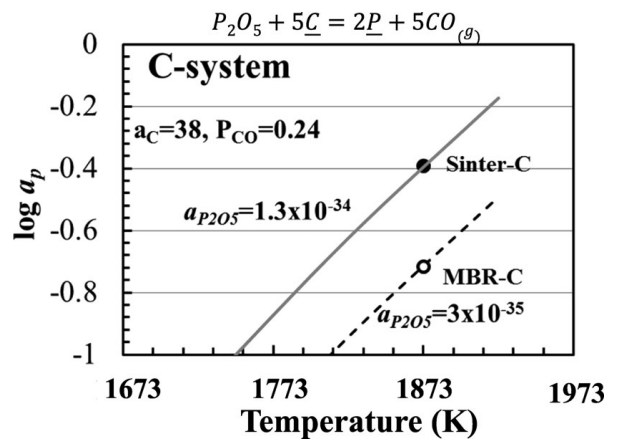

Fig. 15. Temperature dependence of activity of $P$ in the case of carbon reduction: $\mathrm{a}_{2} \mathrm{O}_{5}=1.3 \times 10^{-34}$ or $3 \times 10^{-35}, \mathrm{P}_{\mathrm{CO}}=0.24$, $\mathrm{a}_{\mathrm{C}}=38$.

$\frac{1}{5} P_{2} \mathrm{O}_{5(s)}+\underline{2 H}=\frac{2}{5} \underline{P}+H_{2} O_{(g)}, \Delta \mathrm{G}^{\circ} / J=-61778.4-111.36 \cdot \mathrm{T}$

On the other hand, $\mathrm{P}_{2} \mathrm{O}_{5}$ reduction by the dissolved carbon is expressed by Eq. (33), which is estimated by Eqs. (30)-(32). The temperature dependence of activities of phosphorus, $a_{P}$ was plotted in Fig. 15, when $a_{C}$ was equal to 38 and $\mathrm{P}_{\mathrm{CO}}$ was 0.24 , and $a_{P_{2} O_{5}}$ are $1.3 \times 10^{-24}$ and $3 \times 10^{-24}$ for sinter-C and MBR-C, respectively.

JSPS:

$P_{2} \mathrm{O}_{5(s)}+5 C_{(s)}=P_{2(g)}+5 C O_{(g)}, \Delta \mathrm{G}^{\circ} / J=1044980-974.9 \cdot \mathrm{T}$

$P_{2(g)}=2 \underline{P}$, $\Delta \mathrm{G}^{\circ} / J=-315700+10.79 \cdot \mathrm{T}$

$C_{(s)}=\underline{C}$, $\Delta \mathrm{G}^{\circ} / J=24740-43.51 \cdot \mathrm{T}$

$\frac{1}{5} P_{2} \mathrm{O}_{5(s)}+\underline{C}=\frac{2}{5} \underline{P}+C O_{(g)}, \quad \Delta \mathrm{G}^{\circ} / J=121116-149.3 \cdot \mathrm{T}$

It was found that the activity of $\mathrm{P}_{2} \mathrm{O}_{5}$ in the carbon reduction is lower than that in the hydrogen reduction. This result would also be related to the higher oxygen activity in the 
case of hydrogen reduction.

\subsection{Thermochemical Analyses of the Reduction Reac- tions of $\mathrm{SiO}_{2}, \mathrm{MnO}$ and $\mathrm{P}_{2} \mathrm{O}_{5}$}

In this section, the $\Delta \mathrm{G}\left(=\Delta \mathrm{G}^{\circ}+\mathrm{RT} \ln \mathrm{K}\right)$ for respective reduction reactions of $\mathrm{SiO}_{2}, \mathrm{MnO}$ and $\mathrm{P}_{2} \mathrm{O}_{5}$ using the obtained activities and partial pressures of gases were evaluated and compared with the $\Delta \mathrm{G}^{\circ}$. From Figs. 16 to $18, \Delta \mathrm{G}$ and $\Delta \mathrm{G}^{\circ}$ for the hydrogen reaction and carbon reduction are plotted, where the distance between $\Delta \mathrm{G}$ and $\Delta \mathrm{G}^{\circ}$ means the amount of $\mathrm{RT} \ln \mathrm{K} . \Delta \mathrm{G}=0$ means an equilibrium state of reaction. When $\Delta \mathrm{G}$ is negative $(\Delta \mathrm{G}<0)$, the reaction will proceed toward the right hand side. Inversely, when $\Delta \mathrm{G}$ is positive $(\Delta \mathrm{G}>0)$, the reaction will proceed to the opposite direction.

$\mathrm{SiO}_{2}$ reduction by hydrogen dissolved in the molten metal is expressed by Eq. (11') and the $\Delta \mathrm{G}^{\circ}$ is expressed by Eq. (11). Then, $\Delta \mathrm{G}$ can be calculated by Eq. (34) where $a_{S i}$ is $0.019, P_{\mathrm{H}_{2} \mathrm{O}}$ is $2.5 \times 10^{-4}, a_{\mathrm{SiO}_{2}}$ is 1.0 and $a_{\mathrm{H}}$ is $1 \times 10^{-4} . \Delta \mathrm{G}$ of Eq. (34) is shown in Fig. 16 in comparison with the $\Delta \mathrm{G}^{\circ}$ of

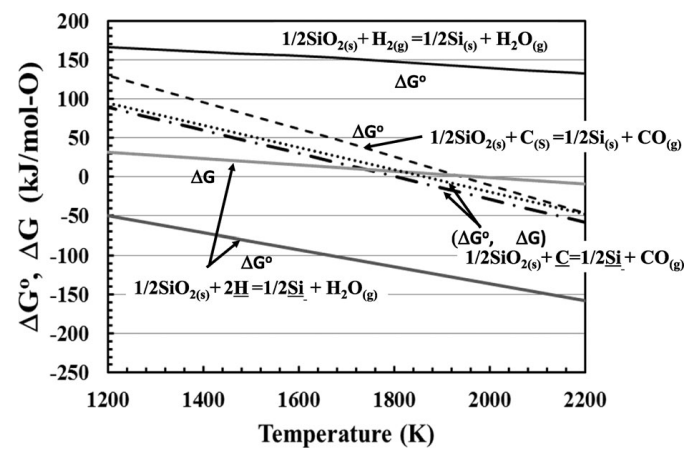

Fig. 16. Comparison of $\Delta \mathrm{G}^{\circ}$ and $\Delta \mathrm{G}$ of reduction reactions of $\mathrm{SiO}_{2}$ by hydrogen and carbon.

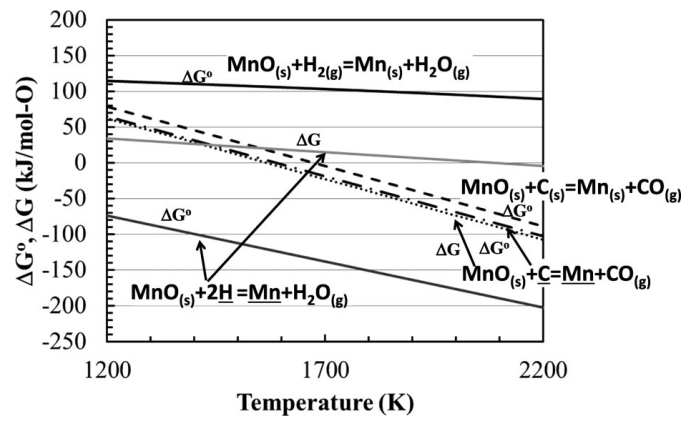

Fig. 17. Comparison of $\Delta \mathrm{G}^{\circ}$ and $\Delta \mathrm{G}$ of reduction reactions of $\mathrm{MnO}$ by hydrogen and carbon.

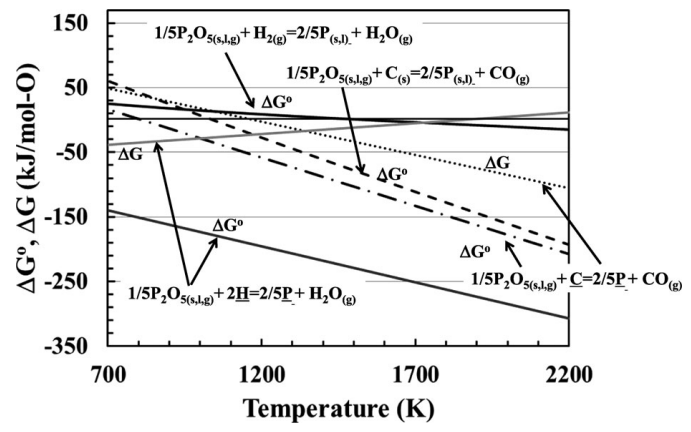

Fig. 18. Comparison of $\Delta \mathrm{G}^{\circ}$ and $\Delta \mathrm{G}$ of reduction reactions of $\mathrm{P}_{2} \mathrm{O}_{5}$ by hydrogen and carbon.
Eqs. (1) and (11) with solid lines. $\Delta \mathrm{G}^{\circ}$ of Eq. (1) is always positive and the reaction never occurs, thermodynamically. On the other hand, the $\mathrm{SiO}_{2}$ reduction by hydrogen dissolved in the molten metal (Eq. (11)) is always minus and the reaction is easy to proceed toward right hand side. These results of $\Delta \mathrm{G}^{\circ}$ are not adequate to explain the experimental result. $\Delta \mathrm{G}$ from Eq. (34) becomes minus at $1970 \mathrm{~K}$. Since the experimental temperature was $1873 \mathrm{~K}$, the $\mathrm{SiO}_{2}$ reduction by hydrogen would not occur. However, this result predicts that the reduction reaction will proceed in the higher temperature above $1973 \mathrm{~K}$, although the driving force is not so large.

$$
\begin{gathered}
\mathrm{SiO}_{2(s)}+4 \underline{H}=\underline{\mathrm{Si}}+2 \mathrm{H}_{2} \mathrm{O}_{(g)} \\
\Delta G=\Delta G^{\circ}+R T \operatorname{Tl}\left(\frac{a_{\mathrm{Si}_{1} \cdot P_{\mathrm{H}_{2} \mathrm{O}}^{2}}}{a_{\mathrm{SiO}_{2}} \cdot a_{\mathrm{H}}^{4}}\right)
\end{gathered}
$$

Similarly, The $\Delta \mathrm{G}$ and $\Delta \mathrm{G}^{\circ}$ of carbon reductions of $\mathrm{SiO}_{2}$ are compared in Fig. 16 with broken lines. The dashed line means the $\Delta \mathrm{G}^{\circ}$ of Eq. (4) which already mentioned above and becomes minus from $1943 \mathrm{~K}$. In the case of Eq. (13') which is the reduction by dissolved carbon (dotted and dashed line), the $\Delta \mathrm{G}^{\circ}$ becomes minus from $1796 \mathrm{~K}$ which is the lower temperature than that of Eq. (4). When the activities obtained in this study was used for the calculation of $\Delta \mathrm{G}$ of Eq. (35)(dotted line), the result become minus from $1867 \mathrm{~K}$, which means the reaction proceeds forward at the experimental temperature of $1873 \mathrm{~K}$.

$$
\mathrm{SiO}_{2(s)}+2 \underline{\mathrm{C}}=\underline{\mathrm{Si}}+2 \mathrm{CO}(g)
$$

$$
\Delta G=\Delta G^{\circ}+R T \ln \left(\frac{a_{S i} \cdot P_{C O}^{2}}{a_{S_{i O}} \cdot a_{C}^{2}}\right)
$$

The reduction reaction of $\mathrm{MnO}$ by dissolved hydrogen in molten iron is expressed by Eq. (36). $\Delta \mathrm{G}^{\circ}$ and $\Delta \mathrm{G}$ are plotted with solid lines in Fig. 17. The $\Delta \mathrm{G}^{\circ}$ of Eq. (2) is also plotted with solid line in Fig. 17 for the sake of comparison. $\Delta \mathrm{G}$ of Eq. (37) was calculated using the values : $a_{M n}=0.06$, $\mathrm{P}_{\mathrm{H}_{2} \mathrm{O}}=2.5 \times 10^{-4}, \quad a_{H}=1.6 \times 10^{-4}, \quad a_{M n O}=0.01$, which were obtained using experimental data.

Similarly to the $\mathrm{SiO}_{2}$ reduction by hydrogen, $\Delta \mathrm{G}^{\circ}$ of Eq. (2) is always positive and the one for Eq. (36) is negative from low temperature region. Actually, as the content of Mn in the metal was decreased in the hydrogen reduction, the negative $\Delta \mathrm{G}^{\circ}$ for the reaction cannot explain the experimental result. While the $\Delta \mathrm{G}$ of Eq. (37) become negative from $2057 \mathrm{~K}$. As the temperature of experiment was $1873 \mathrm{~K}$, it could explain the result of experiment that the reduction of $\mathrm{MnO}$ by hydrogen did not occur.

On the other hand, the $\mathrm{MnO}$ reduction by carbon between Eqs. (5) and (38) did not show the large difference. The $\Delta \mathrm{G}^{\circ}$ of Eq. (38) decreased and became minus from $1586 \mathrm{~K}$, while the one of Eq. (5) become minus from $1673 \mathrm{~K}$. When the activities of components were taken in account, $\Delta \mathrm{G}$ of Eq. (39) $\left(a_{M n}=0.06, \mathrm{P}_{\mathrm{CO}}=0.24, a_{C}=38, a_{M n O}=5 \times 10^{-4}\right)$ was not changed largely. Then, $\mathrm{MnO}$ reduction by dissolved carbon proceeded at $1873 \mathrm{~K}$, dominantly.

$$
M n O_{(s)}+2 \underline{H}=\underline{M n}+H_{2} O_{(g}
$$




$$
\begin{gathered}
\Delta G=\Delta G^{\circ}+R \operatorname{Tln}\left(\frac{a_{M n} \cdot P_{H_{2} O}}{a_{M n O} \cdot a_{H}}\right) \\
M n O_{(s)}+\underline{C}=\underline{M n}+C O_{(g)} \ldots . . \\
\Delta G=\Delta G^{\circ}+R T \ln \left(\frac{a_{M n} \cdot P_{C O}}{a_{M n O} \cdot a_{C}}\right) .
\end{gathered}
$$

Figure 18 shows the $\Delta \mathrm{G}^{\circ}$ and $\Delta \mathrm{G}$ of the reduction reaction of $\mathrm{P}_{2} \mathrm{O}_{5}$ with hydrogen and carbon. Although the $\Delta \mathrm{G}^{\circ}$ of Eq. (6) become minus from $1563 \mathrm{~K}$, the one of Eq. (29) is always minus which cannot explain the result of experiment. When the activities of components are taking into account in Eq. (40), $\Delta \mathrm{G}$ shows the positive slope and becomes positive from $1823 \mathrm{~K}$, which means that the hydrogen reduction does not occur in higher temperature. These results indicate that the $\mathrm{P}_{2} \mathrm{O}_{5}$ reduction by hydrogen might easily change to the opposite direction with the condition of experiment.

$$
\begin{gathered}
\frac{1}{5} P_{2} \mathrm{O}_{5(s)}+\underline{2 H}=\frac{2}{5} \underline{P}+H_{2} O_{(g)} \\
\Delta G=\Delta G^{\circ}+R T \ln \left(\frac{a_{P}^{2 / 5} \cdot P_{H_{2} O}}{a_{P_{2} O_{5}}^{1 / 5} \cdot a_{H}^{2}}\right) \\
\frac{1}{5} P_{2} \mathrm{O}_{5(s)}+\underline{C}=\frac{2}{5} \underline{P}+C O_{(g)} \cdots . . . \\
\Delta G=\Delta G^{\circ}+R T \ln \left(\frac{a_{P}^{2 / 5} \cdot P_{C O}}{a_{P_{2} O_{5}}^{1 / 5} \cdot a_{C}}\right) .
\end{gathered}
$$

The $\mathrm{P}_{2} \mathrm{O}_{5}$ reduction by carbon occurs from lower temperature. In the case of the reduction by solid carbon, $\Delta \mathrm{G}^{\circ}$ of Eq. (3) becomes minus from $1043 \mathrm{~K}$, while the reduction by dissolved carbon (Eq. (33)) becomes minus from $808 \mathrm{~K}$. When the activities of components $\left(a_{P}=0.398, \mathrm{P}_{\mathrm{CO}}=0.24\right.$, $a_{C}=38, a_{P_{2} O_{5} n}=1.3 \times 10^{-24}$ ) are taken into account to Eq. (41), $\Delta \mathrm{G}$ becomes minus from $1173 \mathrm{~K}$ which moves toward high temperature region.

$\Delta \mathrm{G}$ of the reductions by hydrogen and carbon are crossing at $1363 \mathrm{~K}$. From these consideration, the reduction of $\mathrm{P}_{2} \mathrm{O}_{5}$ by dissolved carbon is dominant in the higher temperature region more than $1363 \mathrm{~K}$, and the one by dissolved hydrogen is dominant in the lower temperature region.

However, the observation results between the hydrogen and carbon reduction did not show the clear difference, because the hydrogen reduction would be changed the direction in accordance with the experimental condition.

\section{Conclusions}

Two kinds of iron ore were reduced and melted both under hydrogen and carbon atmosphere. The obtained iron metal under hydrogen atmosphere was quite pure one. The impurities in the metal were chemically analyzed and thermodynamically examined. The characteristics and benefits of hydrogen reduction were discussed in comparison with the carbon reduction. The obtained results are summarized as follows:

(1) The iron metal obtained by the hydrogen reduction had high purity. The content of silicon was one tenth to the iron obtained by carbon reduction. Manganese was about one third to one tenth for the carbon reduction. However, phosphorus in the hydrogen reduction was almost the same level to the carbon reduction.

(2) Sulfur content also became half in the hydrogen reduction.

(3) However, the content of hydrogen was the same level between the hydrogen reduction and the carbon reduction. It was found that the rate of hydrogen evolution from a molten metal during solidification was fast significantly.

(4) The activities of elements (C, Si, Mn, P, S, Al, O, $\mathrm{Ca}, \mathrm{Mg}, \mathrm{H})$ in iron metal were calculated based on the thermochemical data, and the relationships among those elements were elucidated.

(5) From the thermodynamic analysis, a high oxygen activity in the metal obtained under hydrogen atmosphere caused to a low content of impurities and high activity of oxides related.

\section{Acknowledgement}

A part of this research was supported by Grant-in-Aid for Scientific Research B, (No. 21310061), Japan Society for the Promotion of Science (JSPS).

\section{REFERENCES}

1) H. Kamura: Tetsu-to-Hagané, 9 (1923), 699.

2) H. Kamura: Tetsu-to-Hagané, 17 (1931), 109.

3) J. F. Elliott, M. Gleiser and V. Ramakrishna: Thermochemistry for Steelmaking, Vol. II, Addison-Wesley Publishing Co. Inc., London, (1963).

4) H. Schenck, ed.: Die physikalische Chemie der Eisen- und Stahlerzeugung, Verein Deutscher Eisenhuettenleute, Verlag Stahleisen M. B. H., Duesseldorf, (1964)

5) H. F. Rizzo, R. S. Gordon and I. B. Cutler: J. Electrochem. Soc., 116 (1969), 266.

6) D. R. Stull and H. Prophet: JANAF Themochemical Table, 2nd ed., NSDRS-NBS37, US Government printing office, Washington, DC, (1971).

7) R. A. Giddings and R. S. Gordon: J. Am. Ceram. Soc., 56 (1973), 111.

8) H. W. St. Clair: Trans. Metall. Soc. AIME, 233 (1965), 1145.

9) A. Moriyama, J. Yagi and I. Muchi: J. Jpn. Inst. Met., 29 (1965), 528.

10) R. H. Spitzer, F. Manning and W. O. Philbrok: Trans. Metall. Soc. AIME, 236 (1966), 1715.

11) J. Szekely and J. Y. Wen: AIChE J., 14 (1968), 311.

12) T. Yagi and Y. Ono: Trans. Iron Steel Inst. Jpn., 8 (1968), 377.

13) Y. Hara, M. Tsuchiya and S. Kondo: Tetsu-to-Hagané, 55 (1969), 1297.

14) Outokumpu HSC Chemistry for Windows, Ver. 5.1, ISBN 952-950708-9, Outech Research Oy, Finland, (2002).

15) M. Hino and K. Ito: Thermodynamic Data for Steelmaking, The 19th Committee in Steelmaking, The Japan Society for Promotion of Science, Tohoku University Press, Sendai, (2009).

16) J. F. Elliott, M. Gleiser and V. Ramakrishna: Thermochemistry for Steelmaking, The American Iron and Steel Institute, AddisonWesley Publishing Co. Inc., London, (1963). 